

\title{
ENVIRONMENTAL CONDITIONS AND FOUNDING PROCESSES IN ORGANIZATIONAL CREATION: A COMPARATIVE CASE STUDY ${ }^{1}$
}

\author{
by
}

\author{
Agnes G. Meinhard \\ Faculty of Business \\ Ryerson Polytechnic University
}

\begin{abstract}
One of the most important factors in an organization's establishment is the acquisition of legitimacy. This comparative case analysis reveals an unexpected relationship between legitimacy and organizational founding processes.
\end{abstract}

\section{Introduction}

The organizational infrastructure institutionalized during the founding process of an organization provides the imprint for its growth, future direction and ultimate survival. Both internal and external factors play their parts in determining the eventual form the organization will take (Stinchcombe, 1965). Generally speaking, research on organizational creation can be divided into two basic categories: studies investigating ecological/ environmental factors affecting organizational creation and survival (e.g. Carroll and Delacroix, 1982; Delacroix and Carroll; Freeman, Carroll and Hannan, 1983; Tucker, Singh and Meinhard, 1990) and those looking at internal founding processes (e.g. Kimberley, 1980; Miles and Randolph, 1980; Van de Ven, 1980).

The interaction between external conditions and the internal founding process has been but infrequently investigated. Wiewel and Hunter (1985), in a case analysis of two neighbourhood development organizations, demonstrated how different pre-existing organizational densities in the communities they studied differentially affected the founding processes of the focus organizations. They found that contrary to expectations of adverse competitive pressures, the existence of similar organizations helped, rather than hindered the newly formed entities, by providing resource exchange, legitimation and domain definition.

The research reported here is a comparative case analysis of the formation of two non-profit egalitarian prayer groups, ${ }^{2}$ one in Hamilton, Ontario, and the other in Mevasseret Zion, Israel. These two voluntary associations, very similar in demographic make-up, had identical aims at the time of their creation, however, their social, religious and political milieus were markedly different. Because of the similarity of goals and member characteristics in diametrically different environments, this study provides a unique opportunity to further elaborate on the impact of external environmental conditions

on the founding processes of organizations. The article will focus on how the presence or absence of external legitimation affected the founding processes of the two fledgling prayer groups, their efforts at resource mobilization and their internal legitimacy.

\footnotetext{
1. I wish to express my gratitude to Shifrah Alleson, who was the moving force behind the Israeli segment of this research, bringing the group to my attention, coordinating the interviews and gathering the archival data. I also wish to thank Agnes Izso for her skilful interviewing in Hamilton. This research was supported, in part, by Internal Grant \# 5-27075 of the Faculty of Business, Ryerson Polytechnic University.

2. In the Jewish tradition, there are certain communal prayers that can be recited only when a quorum of ten males over the age 13 is present. Additionally, there are several rituals which have traditionally been preformed only by adult males, rituals which include being called up to read from the Torah and say the blessings. An egalitarian prayer group is one in which women as well as men are counted in the communal prayer quorum and can participate in every aspect of the synagogue service..
} 
Stinchcombe (1965) identified the acquisition of legitimacy as a fundamental factor in determining an organization's survival prospects. An organization's legitimacy derives from an acceptance by members and outsiders of the organization and its activities. "Legitimacy is the property of a situation or behaviour that is defined by a set of social norms as correct and appropriate" (Scott, 1987:286). Without recognition from the outside, resources from the environment will be unavailable to the organization. External legitimacy relates both to the legitimacy of an organizational form and to the legitimacy of the organization itself. Not only must an organization attain external validation, it must also be legitimate in the eyes of its own members. This is not as obvious as it seems, especially in the early developmental stages, when an organization is struggling to define its goals and coordinate it's activities. Both the organization's goals and its structure have to be legitimate in the eyes of it's members.

\section{Research Setting and Design}

The analysis presented here compares the founding processes of two egalitarian prayer groups, one in Hamilton, Ontario, and the other in Mevasseret Zion, Israel. Initially the study was designed to investigate the introduction of a novel organizational form into an established community by examining the founding processes of a newly formed egalitarian prayer group in Hamilton, Ontario (Meinhard and Izso, 1990). Subsequently, on a visit to Israel the author was informed of the existence of a newly created egalitarian prayer group in a middle-class suburb of Jerusalem, and was invited to attend a meeting. The purpose of the Israeli group was identical to that of the Hamilton group, i.e. to provide an alternative prayer environment where men and women are considered equal and each sex can fully partake in every aspect of the service. Through informal conversations with some of the members of the group it became evident that the socioeconomic, educational, professional and religious background of the Jerusalem group was similar to that of the Hamilton group. All were university educated, many with advanced degrees. Occupationally both groups include university professors, teachers, lawyers, nurses and doctors.

External conditions in Israel however, are very different from those in religiously pluralistic Canada. In Israel, the orthodox religious establishment constitutionally controls all matters concerning religious worship, and neither Reform nor Conservative branches of Judaism have legitimate standing. In Canada there is no orthodox hegemony and all streams of Judaism have vigourous memberships. These vastly different external conditions provided a unique opportunity to investigate the impact of the environment on the internal processes of organizational creation in groups with similar goals and of similar composition.

Data used in this analysis were obtained through participant observation; archival sources including minutes of meetings, correspondence, and written proposals; and in-depth interviews with 10 founding members of the Hamilton group and 13 of the Israeli group as well as a member of the local council of Mevasseret and representatives from the Movement for Progressive Judaism. The study spans the first three years of each organization's existence.

\section{The Communities}

The City of Hamilton is an industrial urban centre with a population of 365,000. It has a very close-knit Jewish community numbering about 5000 individuals who reside mostly in the west end of the city and the neighbouring suburb of Dundas. Hamilton's Jewish community supports all three of the mainstream forms of Jewish religious affiliation: Orthodox, Conservative and Reform (roughly one synagogue per 1,667 people). 
There is a recognition of religious pluralism. In addition, there are many secular Jewish organizations in the city.

Mevasseret Zion is a western suburb of Jerusalem, nestled in the Judean hills, with a population of around 16,000. The municipality has experienced a very substantial growth spurt in the past decade and a half, which has changed its character significantly. In the late 1970's the Government of Israel released acreage in the area to be developed for private homes. Mevasseret has since become a popular choice for upwardly mobile young professionals seeking single family homes in the Jerusalem vicinity. The population today is a mixture of young secular professionals, mostly of European background, religiously more traditional Jews of North African background, and a fair contingent of observant orthodox Jews. There are nine synagogues in the town, (roughly one synagogue per 1,777 people) all of them orthodox. Unlike synagogues in North America, which exist only through the support of their membership and private donations, in Israel, the government, through the Ministry of Religious Affairs, provides places for worship wherever there is a demand. Since the orthodox parties control this ministry, these venues are provided only for orthodox synagogues. Neither Conservative nor Reform forms of religious worship are considered legitimate. Thus, Conservative and Reform congregations have to find their own means of support, usually from their American counterparts. There are only a handful of Conservative and Reform congregations in the entire country.

\section{Founding Processes}

The birth of a new organization marks the beginning of a very precarious journey fraught with challenges both within and outside of the organization. In its earliest stages the organization must find itself a niche in the environment (Hannan and Freeman, 1989). This entails effectively competing with existing organizations for environmental resources and attaining legitimacy both from its own members and from the environment. In addition, the fledgling organization must successfully socialize its new members and achieve role coordination among them (Stinchcombe, 1965).

In neither community was the creation of an egalitarian prayer group simply the addition of a new organization to a network of existing ones. It marked the introduction of a new organizational form. Thus the legitimacy not only of the organizational attempt, but also of the organizational form was an issue from the outset. Hannan and Freeman (1989:132) noted that "those who attempt to create a new form [of organization] must fight for legitimacy; they must argue both for the special purposes proposed by the organization and for the design of the form".

The earliest beginnings of the two groups were remarkably similar, however, at a crucial point in their formation the organizations diverged and institutionalized different organizational structures. It will be argued that the divergence was a result of different legitimacy issues faced by the organizations.

Organizations do not just sprout spontaneously. There is usually a lengthy germination phase between an idea and an organizing attempt. Certain environmental conditions have to be present in order for organizational creations to occur. On a general societal level these factors have been identified as a sufficient degree of population literacy, availability of specialized education, and urbanization (Stinchcombe, 1965, based on the work of Durkheim and Weber). On an individual organizational level, an organization is created both in

response to population demands for the organizational service or product, and as a result of the capacity of the environment to provide the necessary resources (Boulding, 1953).

\section{Population Demand}


In both communities there was a demand for an alternative form of worship. In Hamilton, there were two distinct needs expressed by two separate population segments, that were not being met by the existing institutions. First, there were a number of people who were looking for more meaningful spiritual expression than they could find in their synagogues. The second group consisted almost entirely of women who were affronted by the inequalities inherent in mainstream worship and, to a lesser degree, were interested in taking a more active role in the service.

In Mevasseret the large majority of interviewees expressed a need for spirituality in the context of traditional Jewish ritual, however without the constraints of orthodoxy. Some of them had been members of liberal congregations in North America or even in other Israeli communities, but in Mevasseret there was no alternative to Orthodoxy. Only one of the respondents declared equality and opportunity for women as the main reason for joining. Although this wasn't a predominant condition for the rest of the founding group, many of them, both men and women, mentioned that they enjoyed the egalitarian aspect and that it was a "plus". A majority of the founding members were concerned about giving their children some kind of traditional Jewish background, which they don't get in the secular schools that they attend.

In both communities there had been previous discussions about setting up an alternative prayer group. In Hamilton, many of the founding members had been a part of a study/social group that partially answered these needs, and there had been sporadic discussions of establishing a reconstructionist congregation. In Mevasseret there had been an attempt, several years earlier, to organize special classes in the public school to teach traditional Jewish ritual under a Conservative rather than Orthodox rubric. After a difficult organizing process, this class was active for a year before it was "torpedoed" by the "antisemitic secularists" in the school. Several of the active founders of the Mevasseret congregation were involved in the failed attempt, and they were still bitter about it.

The need, or demand for an alternative style of worship was present in both communities, but nothing happened in either for many years. What were the catalysts that finally activated the idea?

\section{Environmental Capacity}

As mentioned above, certain environmental conditions have to be present in order for organizing activities to take place. In addition to population demand there must be resources available in the environment to support the organization. In the case of Hamilton, the key resources that were missing were knowledge and experience. Within the group of interested people there was no one with sufficient knowledge to lead an independent prayer service, and there was no one with prior experience in organizing a prayer group. In addition to this, interest was not wide enough to have mobilized funds to import a leader. There was never any real attempt, even at an informal level, to organize a prayer group.

These resources became available when a couple who had been very active members in an egalitarian congregation in Toronto moved to Hamilton. They brought with them liturgical knowledge as well as experience with an egalitarian prayer group. A chance encounter between the couple and the president of Hamilton's only Jewish feminist women's organization proved fruitful. She mobilized her extensive organizational skills and contacted several interested people who eventually turned out to be important contributors to the formation and development of the group. The stage was set for the creation of a new 
organization. Finally the key resources, knowledge of liturgy and organizing capacity, had become available to meet the underlying demand.

Just as in Hamilton, in Mevasseret there had been an underlying need for an alternative means of worship, as expressed by all of the people interviewed, however this need was less articulated in the Mevasseret community, remaining at a personal level. One of the key differences between the two communities is that in Hamilton, many of the founding members of the congregation had already been part of an earlier study group, where they had discussed the idea of an alternative form of worship. Although those who had been involved in the failed attempt at creating the educational alternative were interested in having a liberal synagogue, they were too "burned out" to start organizing again.

In Mevasseret the catalyst was a new immigrant to Israel who had had experience in organizing a similar kind of prayer group in North America. Through her efforts a core group of interested people emerged. Although now there was an organizational capacity, what was still lacking was the knowledge base. For this the fledgling group turned to the Movement for Progressive Judaism ${ }^{3}$ who agreed to provide them with a volunteer student rabbi for study groups and the occasional Friday evening services, if they had a core group of 10 interested people.

In both communities, before the idea for an egalitarian prayer group could actually bear fruit much work had to be done in terms of coordination. The essential resource for a group like this is people and the energy that they would bring towards the enterprise. A handful of key families and individuals started contacting people, quietly informing them of their ideas. Through these informal contacts it soon became clear, in both groups, that there were enough people enthusiastic about the idea to make it a distinct possibility.

In Hamilton, 14 families were represented at their initial planning meeting where the nature and frequency of services was discussed, as well as possible venues and the acquisition of essential resources such as prayer books and a Torah scroll. In Mevasseret as soon as there were 10 interested families they met with the student rabbi and they too began discussing the nature of the group. Initially there was a split in goals with some people interested in having study groups and others wanting regular services. Some study groups were arranged as well as a Friday night service. For both groups the first communal ritual was a Friday night service, and in both cases it was an unqualified success with many more than the initial families attending. This gave added impetus to their organizational endeavours.

Until this point in their development, the history of the two groups was analogous. Both were very informally structured, with people volunteering on an ad hoc basis to carry out certain tasks. There was a recognition of informal leadership in both groups in terms of vision and organizing effort, but there was no formalized structure in either of the groups. This parallel development diverged when the groups had to interact with the environment in a formal way. For both groups this centred around the question of venue: finding a suitable place to hold services.

\section{External Legitimacy}

3. For several years the Movement for Progressive Judaism (affiliated with American Reform Judaism) had been trying to gain a foothold in Israel. In spite of the fact that according to Israeli law they are not a legitimate religious body and their rabbis are not allowed to perform life-cycle events such as marriage, divorce, and burial, the movement had established a few congregations in Israel, as well as a rabbinical seminary in Jerusalem. 
When reviewing the early days, almost all of the interviewees in both cities recalled an acute awareness of existing and potential opposition to their endeavours. They recognized that the type of organization they were interested in establishing was not "legitimate" in the eyes of many people. In each group there were those who advised caution with an injunction to move slowly, not to ruffle the feathers of the establishment. This bears witness to concerns that the attempt to organize might be thwarted before it even got off the ground.

The perceptions were the same in both groups, however the form of external opposition was different. In Hamilton, they had less opposition than expected. With the concept of religious pluralism firmly entrenched in Canada, opposition to the new group was expressed in subtle ways only, and there was support, in varying degrees, from some of the established institutions in the city. The major source of opposition was from the rabbi of the orthodox synagogue, who spoke to several of the members in an unsuccessful attempt to dissuade them from participating in the new organization.

Since many of the founding group were members of the Conservative synagogue, there was a strong desire to hold services in the synagogue's auxiliary chapel. This can be interpreted as an attempt to gain legitimacy in the eyes of both their own membership and the community at large. A formal request to the ritual committee of the Conservative synagogue to use their auxiliary chapel was rejected for fear that some of their congregants might prefer to attend the alternative service. They were willing, however, to provide prayer books. The Reform Temple, on the other hand, freely offered their auxiliary chapel. This was used only for three services after which scheduling conflicts forced the group to find another venue. Since that time the group has been meeting, once a month, at Shalom Village, a Jewish senior's residence. The Conservative synagogue continued to provide prayer books, and the Reform temple loaned them a Torah scroll. Thus the group experienced little overt opposition and even received limited legitimation, if not full-fledged acceptance, from the community.

In Mevasseret the situation was very different. The extent and force of the opposition became apparent when the fledgling congregation decided to hold High Holiday services. They began advertising for their High Holiday Services by hanging posters on public bulletin boards and taking out ads in the local newspaper. Their posters were ripped off and threatening phone calls were received in response to the newspaper ads. However, it wasn't until they turned to the local council, the body in charge of allocating space in public buildings and shelters, to request a place in which to hold their High Holiday services, that they realized the extent and strength of the opposition. City councils regularly grant space in public buildings for High Holiday prayers. However the Mevasseret group's request was denied because of political pressure from the orthodox members of council. Nevertheless, the group, spurred on by the many positive responses to their ads and an unexpected source of legitimation in the form of a donation from a reform congregant in the U.S., held their first High Holiday services in very cramped conditions in a private home. It was clear to all, that if they were to continue in any viable way they would have to find a suitable place to hold their services.

This mobilized the group to action, forming committees to write letters and enlist support from lawyers, politicians and the Centre for Pluralism to approach the local council to rescind their decision and provide them with a place. The group also learned that they would have more clout with the local authorities and be eligible for grants from them if they became a registered charity. Charitable registration is one form of attaining legitimacy. In order to become a registered charity an organization has to have an official board of directors. Thus a formal board was nominated. Tasks and positions were clearly defined, and the board was recognized as an official decision-making body.

Community opposition to the group was focused on the fact that it was a new form of organization, an egalitarian prayer group. To the orthodox segment of the population the concept of an egalitarian congregation was anathema, and because of the political clout the orthodox parties hold in Israel, they had real power in 
terms of the resources that the new group needed. An unexpected source of opposition came from a segment of the secular community who abhor any kind of religious expression. The vast majority of the community's secular Jews were uninterested in the struggle.

The group did get crucial external support from the Movement for Progressive Judaism, who provided two alternating student rabbis on a volunteer basis. However, when the group started meeting bi-weekly and then weekly, a rabbi on a volunteer basis was no longer a solution. The congregation turned to the movement to give them a paid rabbi for a half-time position. Now the group had to contend with an administrative apparatus in the Movement which wasn't convinced of the viability of the group, and therefore wasn't ready to make a financial commitment to it. Here the lack of legitimation was towards the group itself, not the new form of organization. As one member put it "We had two fights on our hand. One to get a place to pray, and the other to get meaningful support from the movement." They were forced to make a formal petition to the movement. The board conducted a survey of all their members to impress the Movement with their numbers and gauge the desires of their membership. The Movement requested to meet with the board to discuss all the issues. This strengthened and further formalized the role of the board.

The congregation was successful on both fronts. Thanks to the mobilization of external support, the local council provided the egalitarian group with a venue for the next High Holiday services, and shortly thereafter, a place to hold their weekly prayers. The Movement, impressed by the organization of the group and their numerical strength, decided to lend support by providing the salary for a half-time rabbi.

\section{Internal Legitimacy}

Organizations must be legitimate in the eyes of their own members as well. This is not as obvious as it seems, especially in the early developmental stages, when an organization is struggling to define its goals and coordinate it's activities. Both the organization's goals and its structure have to be legitimate in the eyes of it's members. The definition of organizational domain and goals is an evolutionary process. In both groups there were discussions about the goals and there were challenges to the domain definition, i.e. how often to have services, what kind of services, what other activities to provide besides services etc.

The members of the Hamilton egalitarian group had been struggling since the beginning to define the direction in which they wanted the organization to go, both in terms of ritual practices and whether or not to affiliate with a movement; and in terms of administrative structure. Each year there were animated discussions about holding High Holiday services. Each year the idea was rejected. Too many members were still committed to their old synagogues. Thus internal legitimacy was not very strong. With other acceptable alternatives for most of the members, the Hamilton egalitarian prayer group remained simply an ancillary form of worship, holding Sabbath services only once a month.

Near the end of the first year of its existence the Israeli group experienced a crisis when it was debated which movement to affiliate with, the Conservative Movement or the Movement for Progressive Judaism. The resolution of the crisis, with its resultant decision to affiliate with the Movement for Progressive Judaism, caused some people to leave the group, but strengthened the legitimacy of the group with the remaining members. The success of the High Holiday services held that year further strengthened the group's legitimacy in the eyes of its members.

\section{Organizational Growth}


Although the two organizations in this study started out in answer to similar needs, in very similar ways, and although their demographic make-up was almost identical, at the conclusion of the first three years of their existence, there was a significant difference between the two groups. The Hamilton group was stagnating, while the Israeli was experiencing rapid growth.

The Hamilton group peaked in its paid membership after the first year of existence, at 12 families, with an additional 10 families on the mailing list and attending services sporadically. After three years there was a slight attrition. Services were still held once a month with no holiday services. Average attendance was 12-15 adults. Study groups, which had been regularly scheduled at about one a month in the first year or so, had become sporadic by the third year.

In Israel the growth rate has been steady, and after three years there were 50 paid member-families, and an additional 50 families on the mailing/calling list. Frequency of services increased from once a month to twice a month to weekly. Services were held for every holiday as well. There were regularly scheduled study groups twice a month. Attendance at services averaged between 20 to 30 adults each week, peaking at over 80 adults on some holidays.

\section{Discussion and Conclusions}

The description of the founding processes of the two organizations presented above, suggests that the different environmental conditions experienced by the two organizations had a profound impact on their subsequent development. The key environmental differences were the degree of the opposition to the new groups, and the existence of viable alternatives for the members. Both of these factors affected the internal legitimacy of the groups. Both internal and external legitimacy seem to have had an impact on structural development, and organizational growth.

In Hamilton, where external legitimacy was forthcoming from most of the community, internal legitimacy was weak. The majority of the members were affiliated with one of the mainstream synagogues, which provided them with a viable alternative, especially for holidays. In the absence of a major external issue with which to contend and with the repeated rejection of establishing services for the High Holidays, both of which would have required intense organizational activity, the group was able to function adequately on an ad hoc basis. Organizational meetings were infrequent. The need for growth was acknowledged and constantly discussed, but bids at outreach were sporadic. Suggestions for formalization, in particular with regard to an executive leadership, were repeatedly overruled. An informal structure without clear leadership, was institutionalized.

In Israel, the lack of external legitimacy helped to strengthen the internal resolve of the group. From the interviews with the members, it is obvious that the extent of the opposition towards their efforts served to increase their group's legitimacy in their own eyes. They were no longer only fighting for their own survival. It became a fight for the principle of establishing the right to have diverse forms of worship in their community and the country at large. A lack of viable alternatives for spiritual expression (orthodoxy being unpalatable to all but one of the interviewees), augmented the importance of the survival of this group. Membership recruitment is an important activity of the group. There is a special portfolio on the board of directors focused on advertisement and recruiting.

Three challenges galvanized the Mevasseret congregation and led to the creation of a more formalized structure: Preparation for the High Holidays, the struggle with the local council regarding a place to pray, and 
the petition to the Movement for Progressive Judaism to pay for a part-time rabbi. All of these involved establishing legitimacy in the face of hostility.

Other explanations can be proposed to account for the observed differences between the groups. The higher growth rate of the Mevasseret congregation may merely be a result of a larger pool of unaffiliated people in the community, therefore one cannot expect a similar rate of growth. Two facts weaken this contention. 1) Growth is a result of recruitment strategy, word of mouth dissemination, and the vision to create a needed service. Therefore it can be argued, that growth is affected by internal organizational processes. In Hamilton there had been no real effort to recruit new members. So although some of the differential growth may be accounted for by the size of the pool of potential members, it is not likely to be the entire explanation. In Mevasseret there was active recruitment whereas in Hamilton the importance of outreach to the community was often discussed, but there were no formal efforts to recruit new members. New people would come to services having heard about them informally. 2) An organization must be seen as legitimate by potential clients/users/members. A voluntary organization must "consciously appeal to the interests and needs of other individuals in order for it to grow in members. " (Gartner, 1993.) It is possible that the group does not attract more new members because, of the infrequency of Sabbath services, and the absence of holiday services. It is perceived, even by its own members as marginal and with circumscribed legitimacy.

Differences in organizational development may be explained by founder characteristics (see review by Gartner, 1985). However theorists have refuted the viability of this perspective as sufficient explanation (e.g. Aldrich, 1990). It is true that the spirit and vision of a founder can have an impact on the development of an organization, but not to the exclusion of other factors. Furthermore, it is difficult to unravel the interaction between founders' decisions and the environment. To state again a point which has been emphasized throughout, the early stages of the founding processes were almost identical in the two groups, even in frequency of meetings. The divergence took place only at the stage when the groups turned to the environment for resources.

Internal group dynamics may provide another alternative explanation (Katz, 1993). However, here too it is difficult to unravel the interaction between the environment and group dynamics. It is clear that certain events in Mevasseret galvanized the group to change their dynamics, events which did not occur in Hamilton.

Although these are all plausible explanations for the observations reported in this study, none of them rule out the impact of the environment on founding processes. Founder characteristics and group dynamics can be seen as intervening variables between environmental effects and organizational processes and outcomes.

This study lends support to Wievel's and Hunter's (1985) contentions that, despite competitive pressures, preexisting organizations are often a critical resource for new organizations. In Hamilton the existing synagogues, notwithstanding some competitive concerns, provided the group with much needed resources. In Mevasseret the support of the Movement for Progressive Judaism was absolutely crucial to its development.

The findings of this study are somewhat counter-intuitive. Stinchcombe (1965) hypothesized that lack of external validation would be detrimental to survival probabilities. Ecological studies have found that environmental adversity and lack of legitimation decrease the probability of survival ( Singh, Tucker and House, 1986). Although in this study, both organizations were still alive at the time of observation three years after their founding, the organization facing adversity had grown rapidly, while the other stagnated. Some support for this phenomenon can be found in the ecological literature. Organizations created in munificent environments, when barriers to entry are low, have a lower survival propensity than organizations created in hard times (Tucker, Singh and Meinhard, 1988). Although ecological studies can only speculate as to why this 
might be so, for example in adverse environments greater attention must be paid to proper procedure and control, qualitative analysis such as this study, can elaborate on the processes involved.

In response to the opposition it encountered, the Mevasseret congregation mobilized internal resources, and enlisted support from another segment of the environment. Through enlisting the support of lawyers, politicians and the Centre for Pluralism, the Mevasseret group gained external legitimacy through "nested power"- the calling upon other sources to make their demands effective (Stinchcombe, 1968). These activities served to increase their visibility in the community, which not only led to more positive interest in the group, but also to renewed negative backlash. In Hamilton, where the environment was supportive, the availability of alternatives detracted from the commitment to the egalitarian congregation thus creating ambivalent internal legitimacy resulting in decisions which limited their operations and which affected their legitimacy as perceived by prospective members.

In summary, this comparative case analysis demonstrated the relationship between an organization's external environment and its internal founding processes. One of the most important factors in an organization's growth and survival is the acquisition of legitimacy. New organizational forms are particularly prone to external opposition. This lack of legitimation from the environment makes the acquisition of needed resources more difficult, thereby placing the new organization in a precarious situation. The analysis of two egalitarian prayer groups, similar in purpose and demographic characteristics, revealed a paradoxical situation. The organization with greater initial environmental hostility ended up with stronger internal legitimacy and a more formalized structure to help it contend with the challenges of the environment. Through mobilization of external support to combat the opposition, and provision of regular services, it achieved external legitimacy among potential members and grew rapidly. On the other hand, the organization created in a friendly environment, in which there was no need to struggle for resources, lacked a high degree of internal legitimacy and failed to grow.

The results of case studies are not generalizable to all organizations. However, they provide an important method for disclosing processes that can help explain relationships between environmental conditions and organizational outcomes reported in surveys.

\section{References}

Aldrich, H. 1979. Organizations and Environments. Englewwod Cliffs, N.J.: Prentice-Hall.

Aldrich, H. 1990. Using and ecological perspective to study organizational founding rates. Entrepreneurship Theory and Practice, 14:7-24.

Boulding, K. 1953. The Organizational Revolution. New York: Harper and Brothers.

Carroll, G. and Delacroix, J. 1982. Organizational mortality in the newspaper industries of Argentina and Ireland: An ecological approach. Administrative Science Quarterly, 27:169-198.

Delacroix, J. and Carroll, G. 1983. Organizational foundings: An ecological study of the newspaper industry of Argentina and Ireland. Administrative Science Quarterly, 28:274-291.

Freeman, J. Carroll, G. and Hannan, M. 1983. The liability of newness: Age dependence in organizational death rates. American Sociological Review, 48:692-710. 
Gartner, W.B. 1993. Organizing the Voluntary Association. Entrepreneurship Theory and Practice, 18:104-106.

Hannan, M. and Freeman, J. 1989. Organizational Ecology. Cambridge, Mass.: Harvard University Press.

Katz, J. 1993. The dynamics of organizational emergence: A contmeporary group perspective. Entrpreneurship Theory and Practice, 18:97-101

Kimberley, J. 1981. Initiation, innovation and institutionalization in the creation process. In Kimberley, J. and Miles, R. (eds) The Organizational Life Cycle, San Francisco: Jossey-Bass.

Meinhard, A.G. and Izso, A. 1990. The organizational genesis of an egalitarian prayer group. Second Annual Canada-Israel Conference on Social Scientific Approaches to Judaism.

Miles, R. and Randolph, W. 1981. Influence of organizational learning styles on early development. In Kimberley, J. and Miles, R. (eds) The Organizational Life Cycle, San Francisco: Jossey-Bass.

Tucker, D., Singh, J. and Meinhard A. 1988. Founding conditions, environmental selection and organizational mortality. Unpublished Manuscript, McMaster University.

Tucker, D., Singh, J. and Meinhard, A. 1990. Organizational form, population dynamics and institutional change: A study of birth patterns of voluntary organizations. Academy of Management Journal, 33:151-178.

Scott, W.R. 1987. Organizations: Rational Natural and Open Systems, Englewood Cliffs, N.J.: Prentice-Hall.

Singh, J. Tucker, D. and House, R. 1986. Organizational legitimacy and the liability of newness. Administrative Science Quarterly, 31:171-193.

Stinchcombe, A. 1965. Organizations and social structure. In Handbook of Organizations, edited by J. March, pp. 153-193. Chicago: Rand-McNally.

Stinchcombe, A. 1968. Constructing Social Theories, New York: Harcourt, Brace and World.

Van de Ven, A. 1981. Early planning, implementation and performance of new organizations. In Kimberley, J. and Miles, R. (eds) The Organizational Life Cycle, San Francisco: Jossey-Bass.

Wiewel, W. and Hunter, A. 1985. The interorganizational network as a resource: A comparative case study on organizational genesis. Administrative Sciences Quarterly, 30: 482-496. 